the expensive hardware of last year is this year's dusty junk. (3) Above all, beware of creating more than one master copy of the latest version. If the text you have spent all day revising does not include yesterday's hard worked changes but is based instead on an earlier, unrevised version, hours of human effort will be necessary to merge the two sets of modifications into a single useful master copy.

In maternity care two further fundamental warnings apply: beware lest technology is introduced for its own sake, not because it truly improves patients' care; and choice and consumer power come from openness, not from black stripes and inaccessible microchips.

All these principles seem to have been forgotten in moves towards using smart cards as an advance in the provision of maternity care. Such cards are unreadable without expensive technology, too vulnerable to damage or destruction to be used as the master copy, and cannot be used as the master copy because they are not immediately accessible for updating. The use of one of several different types of smart or optical card will too easily lead to a further waste of scanty health resources; other industries should be taking the risks entailed in the standardisation of smart card technology. The electronic master copy of the antenatal record ought to be in the primary health centre frequently backed up, and regularly updated by modem from a variety of other sources and possibly eventually (with potential problems borne in mind) from hand held, mobile devices for collecting data.

Possibly the only reasonable use of a smart card might be as a personally held identification key. If it was available in a clinic such a card would automatically minimise the risk of one mother's data being erroneously entered into another mother's electronic record.

RUPERT FAWDRY Consultant obstetrician and gynaecologis Milton Keynes General Hospital, Milton Keynes MK5 6LD

1 Drife JO. Assessing the consequences of changing childbirth $B M f$ 1995;310:144-5. (21 January.)

\section{Management of the irritable bowel syndrome}

\section{Early reassurance is important part of treatment}

EDITOR,-Recent articles have discussed the management of the irritable bowel from several points of view. R C Spiller argues for a predominantly medical approach to treatment once the hurdles of reassurance and dietary advice have been negotiated, ${ }^{1}$ while Francis Creed emphasise the importance of psychological treatments for selected groups of patients. ${ }^{1}$ Michael J G Farthing explores the relations between the bowel, body, and brain and provides further advice about the importance of making an early, positive diagnosis and of avoiding overinvestigation. ${ }^{2}$

Perhaps the most important moment for patient with the irritable bowel syndrome is the moment when he or she decides to make the first contact with general practice. We know from community based studies that the prevalence of the syndrome in the general population is roughly $20 \%$ but that only between a quarter and a third of patients consult general practitioners. ${ }^{3}$ Work in North America and Britain has shown that the severity and frequency of symptoms alone poorly predict the likelihood of consultation and that concerns that the symptoms represent a serious disease and specific worries about cancer explain much of the difference between those who do and do not consult. ${ }^{4}$ Patients who consult are more likely to have abnormal levels of anxiety and clinical depression than people with the syndrome in the community, in whom affective disorders are much less commonly seen.

This means that we have to provide reassurance. Reassurance requires a direct confrontation of patients' anxieties about cancer and serious disease and an exploration of these beliefs if they are not immediately apparent. Unless this happens early in the course of the medicalisation of the syndrome, further attempts at reassurance, accompanied by repeated negative results of investigations, will probably serve simply to increase anxiety and apprehension about the symptoms and their underlying cause.

The corollary is that initial treatment needs to embrace physical and psychological approaches, and a cognitive approach to symptoms is probably more likely to be successful than a search for "treatable" affective disorders. Gomborone et al recently documented the negative cognition of patients with the irritable bowel syndrome, ${ }^{5}$ and a randomised controlled trial of an early cognitive therapeutic intervention in the syndrome, starting as soon as possible after the first contact with general practice, seems worth while.

ROGER JONES

Department of General Practice,

Division of Primary Health Care,

UMDS,

London SE11 6SP

1 Spiller RC, Creed F. Irritable bowel or irritable mind? $B M \mathcal{F}$ 1994;309:1646-8. (17 December.)

2 Farthing MJG. Irritable bowel, irritable body, or irritable brain? BMF 1995;310:171-5. (21 January.)

3 Jones $R$, Lydeard $S$. Irritable bowel syndrome in the general population. $B M F$ 1992;304:87-90.

4 Kettell J, Jones $R$, Lydeard $S$. Reasons for consultation in irritable bowel syndrome: symptoms and patient characteristics. Br $\mathcal{G}$ Gen Pract 1992;42:459-61.

5 Gomborone JE, Dewsnap PA, Libby GW, Farthing MJG. Selective affective biasing in recognition memory in irritable bowel syndrome. Gut 1993;34:1230-3.

\section{Food intolerance may play a part}

EDrToR,-In his review on the irritable bowel syndrome Michael J G Farthing ignores the evidence that symptoms can, in many cases, be reliably attributed to food intolerance. ${ }^{1}$ As early as 1771 the King's physician, Sir George Baker, presented to the Royal College of Physicians a patient whose abdominal symptoms improved with a diet of "sea biscuits and salt meat."' During the first half of the 20th century several reports of patients with abdominal pain that responded to dietary modification were published from the United States. ${ }^{3}$ Studies have shown that as many as $70 \%$ of patients with abdominal pain and diarrhoea may be successfully managed by $\operatorname{diet}^{34}$; double blind challenges have provided objective evidence of food intolerance. As follow up of patients shows that most of them remain well on diet for long periods the value of successfully identifying food intolerance should not be dismissed. In addition, use of antibiotics (with consequent changes in the gut flora) may be an important factor in the development of the syndrome.

PETER J LEWIS

Southampton SO15 2DT Complementary physician

1 Farthing MJG. Irritable bowel, irritable body, or irritable brain? $B M F$ 1995;310:171-5. (21 January.)

Drummond JC, Wilbraham A. The Englishman's food. London: Jonathan Cope, 1959:254.

Duke WD. Food allergy as a cause of abdominal pain. Arch Inter Med 1921;28:151-65.

4 Jones VA, Hunter JO. Irritable bowel syndrome and Crohn's disease. In: Brostoff J, Challacombe SJ, eds. Food allergy and intolerance. London: Baillière Tindall, 1987:555-69.

5 Jones VA, Wilson AJ, Hunter JO, Robinson JE. The aetiological role of antibiotic prophylaxis with hysterectomy in irritable bowel syndrome. Obstet Gynaecol 1984;5(suppl 1):S22-3.

\section{Author's reply}

EDITOR,-The role of food intolerance in the production of symptoms in patients with the irritable bowel syndrome is interesting but controversial. We should not forget that both the syndrome and perceived food intolerance are common in the community, occurring in roughly a fifth of the population. ${ }^{1}$ It would therefore be expected that the two conditions would quite frequently coincide in the same person without this necessarily implying causality. Actual food intolerance, determined by double blind, placebo controlled food challenge, is reported to occur in $1-2 \%$ of the population. In a large, careful study Nanda et al found that $48 \%$ of 200 patients with the irritable bowel syndrome responded to an exclusion diet, most of whom continued with the diet because of prolonged benefits. ${ }^{2}$ More than half of the initial study group, however, did not benefit in any way. In addition, there was no correlation between the response to the exclusion diet and any particular symptom complex.

Introducing a formal exclusion diet is a substantial undertaking and can considerably disrupt normal life. Some patients with the irritable bowel syndrome are, however, keen to pursue this approach, and those who respond may find dietary restriction less of a burden than their abdominal symptoms. I certainly encourage patients to explore dietary triggers and stated this clearly in my article. I generally guide patients on the groups of foods that are most likely to be associated with abdominal symptoms, such as dairy products and grains. ${ }^{2}$ I am less enthusiastic about formal exclusion diets because I see a large number of patients who have tried this approach and in whom it has failed and because I have found that treating patients with dietary exclusion is less successful than some of the other approaches outlined in the article.

M J G FARTHING

Digestive Diseases Research Centre, London EC1M 6BQ

1 Young E, Stoneham MD, Petruckevitch, Barton J, Rona R. population study of food intolerance. Lancet 1994;343:1127-9. 2 Nanda R, James R, Smith H, Dudley CRK, Jewell DP. Food intolerance and the irritable bowel syndrome. Gut 1989;30: 1099-104.

\section{Proposed new deprivation index}

\section{Has major flaws in its derivation and validation}

EDrToR,-David C E F Lloyd and colleagues propose a new deprivation index for use in general practice, which is based on the proportion of patients exempted from prescription charges because they have a low income. It is therefore a proxy for the proportion of the practice population living in poverty. The authors believe that it has advantages over the indices with which they compare it (Jarman, Townsend, and Carstairs) namely, that it is practice based and can be frequently updated. They correlate it with the established deprivation indices, producing impressive results at health authority level but unfortunately presenting no results at the general practice level, where it is intended to be used.

There are major flaws in the derivation and validation of this index, which will adversely affect its utility as a measure of deprivation for practice populations. As the authors acknowledge, the low income category of exemption from prescription charges overlaps with other categories. For example, people on low incomes with diabetes may prefer to claim exemption on the basis of illness rather than poverty. The proposed index would thus register variation in local attitudes to poverty, with people being more likely to choose the disease option in areas where poverty is most stigmatised. Prescribing analysis and cost (PACT) data depend on the provision and quality of services, which further confound the index. 